\title{
Experimental Study on Microwave-SiC-assisted Catalytic Hydrogenation of Phenol
}

Jing Sun, Zhenyu Jiang, Ke Wang, Faqi Li, Zhanlong Song*, Wenlong Wang*, Xiqiang Zhao and Yanpeng Mao

National Engineering Laboratory for Coal-Fired Pollutants Emission Reduction, Shandong Provincial Key Lab of Energy Carbon Reduction and Resource Utilization, Shandong University, Jinan 250061, China

\section{Supporting Information}

\section{Materials and experimental design}

\subsection{Catalyst preparation and characterization}

\subsubsection{Catalyst Synthesis}

The $\mathrm{ZrO}_{2}, \mathrm{CeO}_{2}$, and $\mathrm{ZrCeO}_{2}$ supports were synthesized by means of a coprecipitation method.

A solution of $2 \mathrm{~mol} / \mathrm{L} \mathrm{ZrO}\left(\mathrm{NO}_{3}\right)_{2} \cdot 2 \mathrm{H}_{2} \mathrm{O}$ was firstly dissolved in dilute nitric acid, and then slowly added to a $4 \mathrm{~mol} / \mathrm{L} \mathrm{NH} \mathrm{N}_{4} \mathrm{OH}$ solution, followed by vigorous stirring for 30 min at ambient temperature. The resultant precipitate was filtered and washed with deionized water until the $\mathrm{pH}$ reached 7 , and then dried at $110{ }^{\circ} \mathrm{C}$ for $12 \mathrm{~h}$. Thereafter, the as-obtained precursor was heated at $500{ }^{\circ} \mathrm{C}$ for $6 \mathrm{~h}$ at $10{ }^{\circ} \mathrm{C} / \mathrm{min}$ in air atmosphere to create the $\mathrm{ZrO}_{2}$ support.

The synthesis of the $\mathrm{CeO}_{2}$ support was similar to that of the $\mathrm{ZrO}_{2}$, with a $2 \mathrm{~mol} / \mathrm{L}$ $\left(\mathrm{NH}_{4}\right)_{2} \mathrm{Ce}\left(\mathrm{NO}_{3}\right)_{6}$ solution used instead of $\mathrm{ZrO}\left(\mathrm{NO}_{3}\right)_{2} \cdot 2 \mathrm{H}_{2} \mathrm{O}$. 
The $\mathrm{ZrCeO}_{2}$ support was synthesized by dissolving a $2 \mathrm{~mol} / \mathrm{L} \mathrm{ZrO}\left(\mathrm{NO}_{3}\right)_{2} \cdot 2 \mathrm{H}_{2} \mathrm{O}$ solution and $2 \mathrm{~mol} / \mathrm{L}\left(\mathrm{NH}_{4}\right)_{2} \mathrm{Ce}\left(\mathrm{NO}_{3}\right)_{6}$ solution in dilute nitric acid with a $\mathrm{Zr} / \mathrm{Ce}$ molar ratio of $1: 1$, and then adding the mixture to a $4 \mathrm{~mol} / \mathrm{L} \mathrm{NH}_{4} \mathrm{OH}$ solution, followed by stirring for $60 \mathrm{~min}$ at room temperature. The following washing, drying, and calcination steps were the same as those of the $\mathrm{ZrO}_{2}$ support detailed above.

The calcined $\mathrm{ZrO}_{2}, \mathrm{CeO}_{2}$, and $\mathrm{ZrCeO}_{2}$ supports were loaded with 2 wt \% Pd by equal impregnation. An aqueous solution of $\mathrm{Pd}\left(\mathrm{NO}_{3}\right)_{2}$ containing $2 \mathrm{wt} \% \mathrm{Pd}$ was mixed with the support, stirred continuously for $30 \mathrm{~min}$, and dried at room temperature for $12 \mathrm{~h}$. Finally, the powder was heated at $400{ }^{\circ} \mathrm{C}$ for $180 \mathrm{~min}$ in air atmosphere. Following the calcination, the fresh catalyst was reduced with $\mathrm{H}_{2}$ purging at a flow rate of 60 $\mathrm{ml} / \mathrm{min}$ at $300{ }^{\circ} \mathrm{C}$ for $1 \mathrm{~h}$. Therefore, $\mathrm{Pd} / \mathrm{ZrO}_{2}, \mathrm{Pd} / \mathrm{CeO}_{2}$, and $\mathrm{Pd} / \mathrm{ZrCeO}_{2}$ catalysts of 2 wt $\%$ were obtained.

\subsubsection{Catalyst Characterization}

The structure of the samples (non-Pd and Pd based catalysts) were determined by X-ray diffraction (XRD) using a Bruker D8 Advance X-ray diffractometer with $\mathrm{Cu} \mathrm{K \alpha}$ radiation at $45 \mathrm{kV}$ and $40 \mathrm{~mA}$ with a step size of $0.04^{\circ}$ in the range of $10^{\circ}-90^{\circ}$.

The mass fraction of $\mathrm{Pd}$ in the Pd based catalysts was tested using an inductively coupled plasma optical emission spectroscopy (ICP-OES, Agilent 5110, USA).

The energy-dispersive X-ray (EDX) elemental mapping images of the samples were taken to illustrate the distribution of $\mathrm{Pd}, \mathrm{O}, \mathrm{Zr}$ and Ce elements using a scanning electron microscope coupled with energy-dispersive X-ray spectroscopy (EDS).

The surface properties of the catalysts were detected by $\mathrm{NH}_{3}$ temperature- 
programmed desorption ( $\mathrm{NH}_{3}-\mathrm{TPD}$, AutoChem II 2920, U.S.A.) and $\mathrm{CO}_{2}$ temperatureprogrammed desorption ( $\mathrm{CO}_{2}$-TPD, AutoChem II 2920, U.S.A.). In these TPD experiments, all samples were first treated in He at $500{ }^{\circ} \mathrm{C}$ for $1 \mathrm{~h}$ and cooled to $50{ }^{\circ} \mathrm{C}$. And then exposed to $20 \% \mathrm{NH}_{3}$ (or $\mathrm{CO}_{2}, 50 \mathrm{~mL} / \mathrm{min}$, He in balance) for $30 \mathrm{~min}$, purged in $\mathrm{He}$ for $1 \mathrm{~h}$ at $100{ }^{\circ} \mathrm{C}$ and heated linearly at $10{ }^{\circ} \mathrm{C} / \mathrm{min}$ to $600{ }^{\circ} \mathrm{C}$ in $50 \mathrm{~mL} / \mathrm{min} \mathrm{He}$.

$\mathrm{NH}_{3}$ or $\mathrm{CO}_{2}$ in effluent was recorded continuously as functions of temperature.

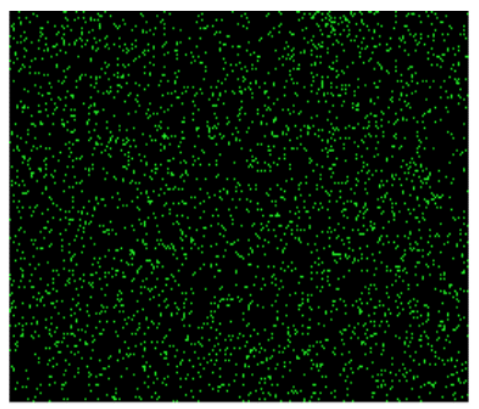

PdLa1

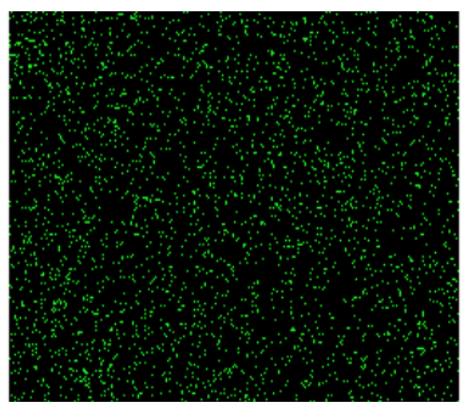

PdLa1

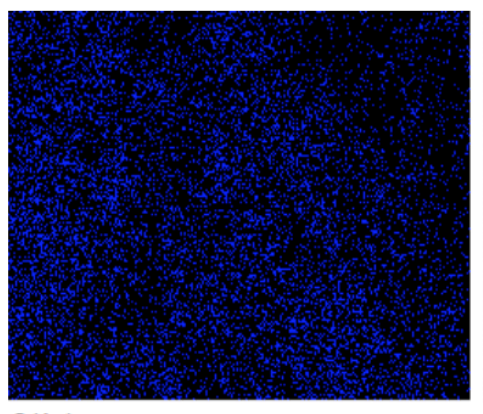

OKa1

(a) $\mathrm{Pd} / \mathrm{ZrO}_{2}$

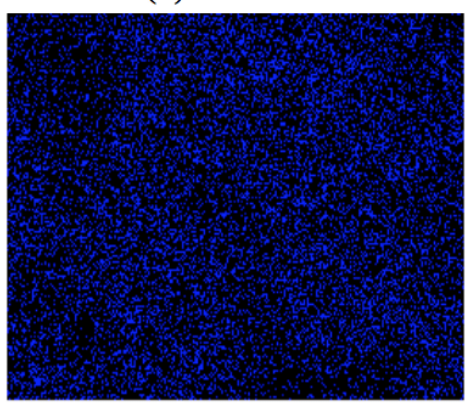

OKa1

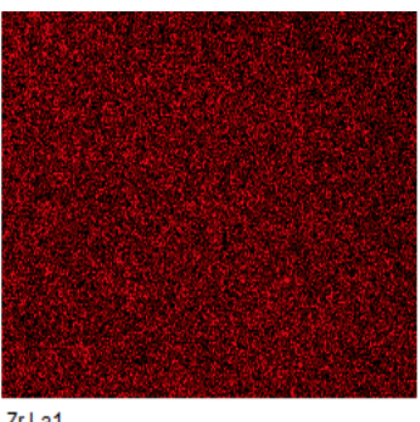

Zr La1

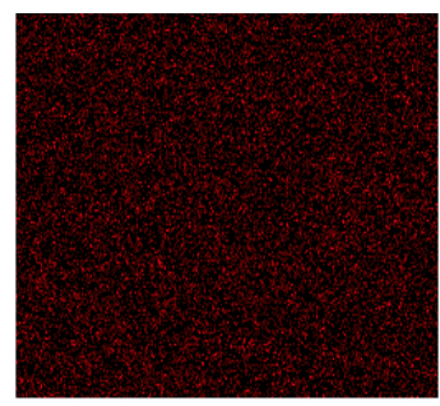

Ce La1

(b) $\mathrm{Pd} / \mathrm{CeO}_{2}$
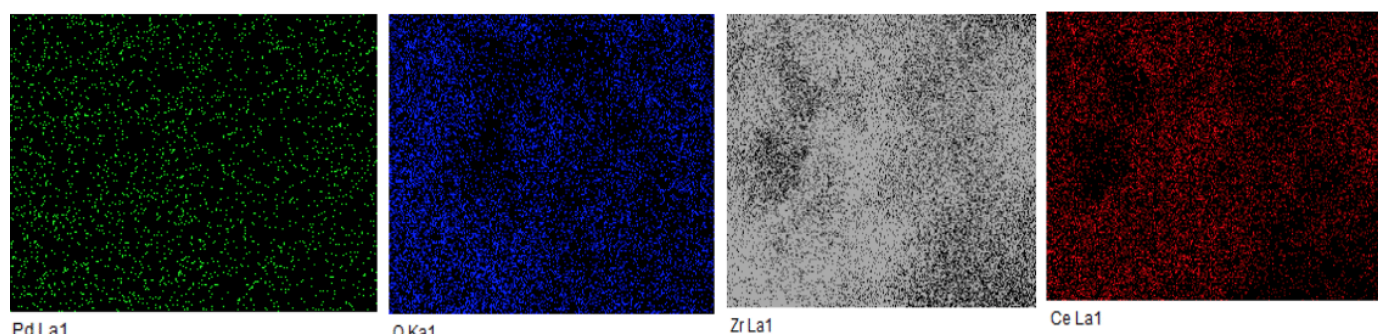

(c) $\mathrm{Pd} / \mathrm{ZrCeO}_{2}$

Figure S1 The elemental mapping images of Pd based catalysts:

(a) $\mathrm{Pd} / \mathrm{ZrO}_{2}$, (b) $\mathrm{Pd} / \mathrm{CeO}_{2}$ and (c) $\mathrm{Pd} / \mathrm{ZrCeO}_{2}$.

\section{Results and discussions}




\subsection{Microwave-induced catalytic hydrogenation of phenol}

Besides the condensable liquid products, $\mathrm{CH}_{4}, \mathrm{CO}$ and $\mathrm{CO}_{2}$ were detected in the gas products via Gas Chromatography. The overall yield as well as the composition of gas products on basis of relative volume percentage at $\mathrm{H}_{2}$ flow rate of 100 and $200 \mathrm{ml} / \mathrm{L}$ respectively was illustrated in Figure S2. Even though the relative proportion varied among the different catalyst supports, the selectivity of $\mathrm{CH}_{4}$ was higher at low $\mathrm{H}_{2}$ flow rate while the selectivity of $\mathrm{CO}_{2}$ was higher at high $\mathrm{H}_{2}$ flow rate, and the selectivity of $\mathrm{CO}$ was relatively low for all scenarios, indicating side reactions such as decomposition occurred in the hydrogenation process.
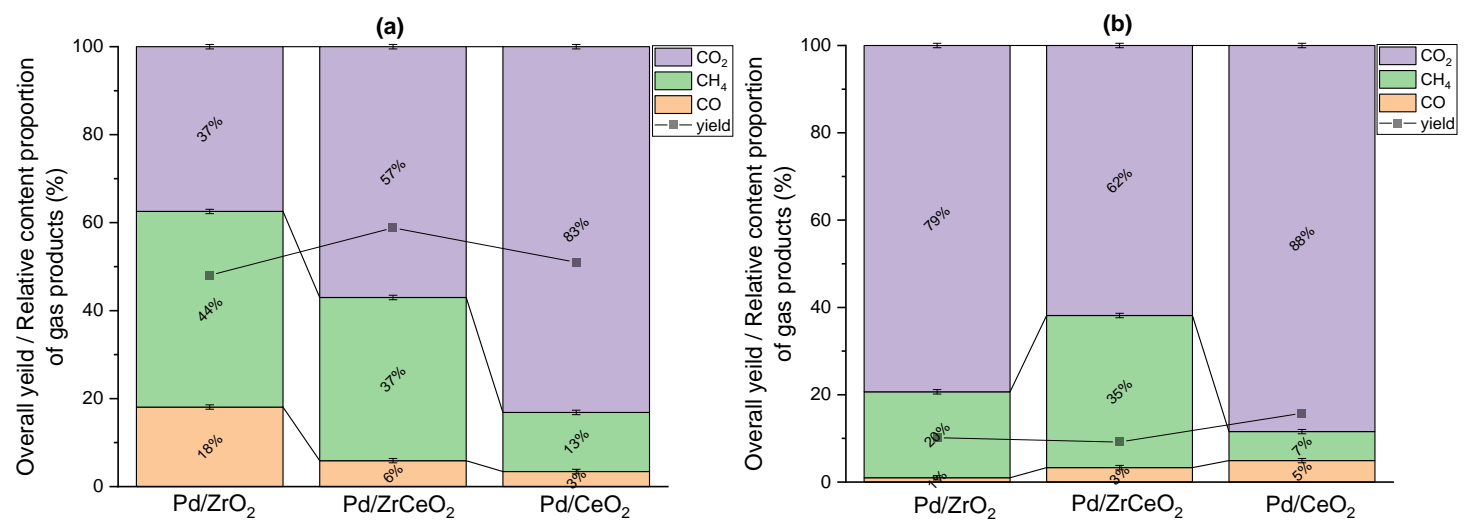

Figure S2 Overall yield and relative content proportion of the gas products for three different catalysts at $\mathrm{H}_{2}$ flow rate of (a) $100 \mathrm{~mL} / \mathrm{min}$ and (b) $200 \mathrm{~mL} / \mathrm{min}$

\subsection{Reaction mechanism of microwave-induced catalytic hydrogenation of phenol}

As the $\mathrm{H}^{\bullet}$ radical plays an important role in the hydrogenation process, specific experiments were designed in this work to validate the formation of $\mathrm{H}^{\bullet}$ radicals with a fiber spectrometer (FX2000-EX, ideaoptics, China). When microwave irradiation was imposed on a mixture of $\mathrm{H}_{2}$ and argon (where argon was used as inert carrier gas) with 
and without SiC particles, the emission spectra were collected with the characteristic spectral lines being interpreted, as illustrated in Figure S3. Obviously, the plasma phenomenon could not be triggered when microwave radiation was exposed only on the given gas mixture without introducing any conductor or semiconductor like $\mathrm{SiC}$ particles. In contrast, characteristic spectral lines were detected when the $\mathrm{H}_{2}$ and argon gas mixture passed through a SiC-particle bed under microwave radiation.

As shown in Figure S3, the characteristic spectral lines were mainly concentrated in the 550-966 nm visible near infrared regions with a few lines in the $200-550 \mathrm{~nm}$ ultraviolet and visible regions. The characteristic spectral lines in the microwave-SiCinduced plasma were mainly divided into two main categories: dielectric materials ( $\mathrm{SiC})$ and atomic hydrogen/argon. According to NIST Atomic Spectra Database (available on https://physics.nist.gov/asd, National Institute of Standards and Technology, Gaithersburg, MD.) and our previous study, most spectral lines concentrated in the 388$924 \mathrm{~nm}$ region, with relatively high intensity, are produced by atomic transitions of hydrogen and argon, as illustrated in Figure S3. According to Table S1, it can be deduced that the presence of $\mathrm{SiC}$ particles enables the generation of excited electrons under the microwave radiation. The excited-state electrons collide with the surrounding hydrogen or argon atoms, and the resulting energy transfer can stimulate hydrogen atoms to generate $\mathrm{H}^{\bullet}$ radicals (plasma) which gives rise to the characteristic hydrogen spectral lines (H I) observed when they return to the ground state. Additionally, there is also the SiC-stimulated spectrum showing peaks at 251.99, 288.29 and $309.75 \mathrm{~nm}$, much lower than those of hydrogen/argon, which can be attributed to their high lattice 
energy in solid phase.

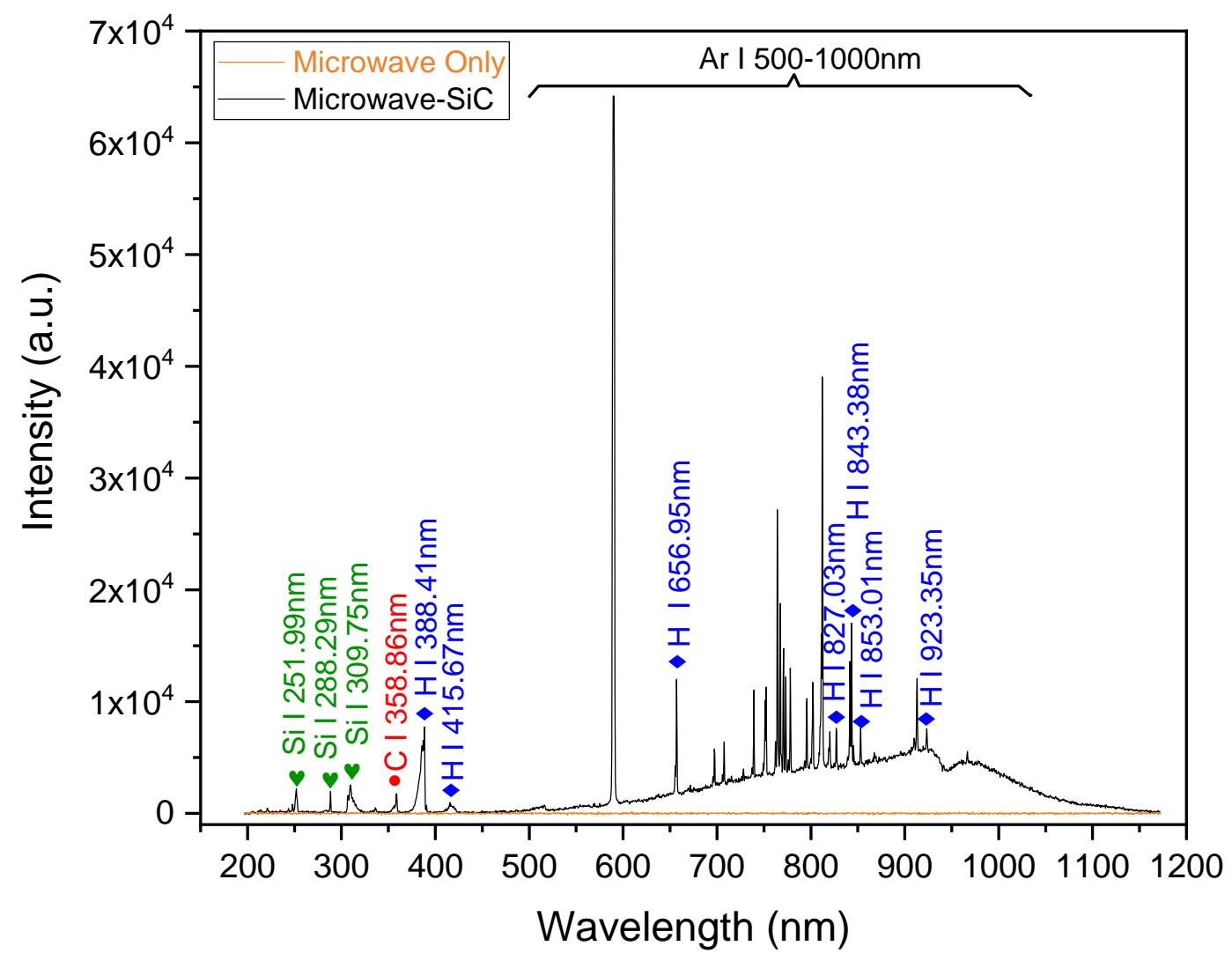

Figure S3 The spectrum captured during the microwave interaction with and without SiC particles at $\mathrm{H}_{2} / \mathrm{Ar}$ atmosphere

Table S1 Most intense emission lines detected in axial spectra of the MW-SiC interaction at $\mathrm{H}_{2} / \mathrm{Ar}$ atmosphere

\begin{tabular}{ccccc}
\hline Species & $\begin{array}{c}\text { Observed } \\
\text { Wavelength } \\
(\mathrm{nm})\end{array}$ & $\begin{array}{c}\text { Ritz } \\
\text { Wavelength }^{a} \\
(\mathrm{~nm})\end{array}$ & $\begin{array}{c}\text { Transition } \\
\text { Probabilities }^{a} \\
A_{k i}\left(\mathrm{~s}^{-1}\right)\end{array}$ & Transition path $^{a}$ \\
\hline Si (I) & 251.99 & 251.92 & $5.49 \times 10^{7}$ & $3 \mathrm{~s}^{2} 3 \mathrm{p}^{2} \rightarrow 3 \mathrm{~s}^{2} 3 \mathrm{p} 4 \mathrm{~s}$ \\
$\mathrm{Si}(\mathrm{I})$ & 288.29 & 288.16 & $2.17 \times 10^{8}$ & $3 \mathrm{~s}^{2} 3 \mathrm{p}^{2} \rightarrow 3 \mathrm{~s}^{2} 3 \mathrm{p} 4 \mathrm{~s}$ \\
$\mathrm{Si}(\mathrm{I})$ & 309.75 & 302.00 & $3.30 \times 10^{3}$ & $3 \mathrm{~s}^{2} 3 \mathrm{p}^{2} \rightarrow 3 \mathrm{~s}^{3} \mathrm{p}^{3}$ \\
C (I) & 358.86 & 359.51 & $\mathrm{n} / \mathrm{a}$ & $2 \mathrm{~s}^{2} 2 \mathrm{p} 3 \mathrm{~s} \rightarrow 2 \mathrm{~s}^{2} 2 \mathrm{p}\left({ }^{2} \mathrm{P}^{\circ}{ }_{1 / 2}\right) 11 \mathrm{p}$ \\
H (I) & 388.41 & 388.90 & $2.21 \times 10^{5}$ & $2 \mathrm{p} \rightarrow 8 \mathrm{~d}$ \\
H (I) & 415.67 & 410.18 & $4.90 \times 10^{5}$ & $2 \mathrm{p} \rightarrow 6 \mathrm{~s}$ \\
H (I) & 656.95 & 656.27 & $5.39 \times 10^{7}$ & $2 \mathrm{p} \rightarrow 3 \mathrm{~d}$ \\
H (I) & 827.03 & 827.19 & $\mathrm{n} / \mathrm{a}$ & $3 \rightarrow 33$ \\
H (I) & 843.38 & 843.80 & $2.58 \times 10^{3}$ & $3 \rightarrow 18$ \\
H (I) & 853.01 & 854.54 & $6.49 \times 10^{3}$ & $3 \rightarrow 15$ \\
H (I) & 923.35 & 922.90 & $8.91 \times 10^{4}$ & $3 \rightarrow 9$ \\
\hline
\end{tabular}

a. These data are based on the NIST Atomic Spectra Database (version 5.7.1). Available online: https://physics.nist.gov/asd. National Institute of Standards and 
Technology, Gaithersburg, MD. DOI: https://doi.org/10.18434/T4W30F 